\title{
The Effects of Breath-Counting Meditation and Deep Breathing on Heart Rate Variability
}

\author{
Ji-Hwan Kim, Hyo-Sang Bae, Seong-Sik Park \\ Department of Sasang Constitutional Medicine, College of Korean Medicine, Dongguk University, \\ Republic of Korea
}

\begin{abstract}
Objectives: This study aimed to evaluate the effects of breath-counting meditation (BCM) and deep breathing (DB) on heart rate variability (HRV). These breathing techniques have the characteristics of non-paced and self-controlled breathings, resulting in less increase of HRV. We also compared BCM and DB with usual breathing (UB) or relaxing breathing $(\mathrm{RB})$ which can reveal the characteristics of those.

Methods: 83 healthy volunteers sitting in chairs performed non-paced breathing; UB, RB, BCM, and DB each for 5 minutes. One minute of relaxation was permitted between breathings. Participants surfed the internet sitting in front of a computer during UB, while for RB, they remained steady with eyes closed. For BCM, they breathed inwardly counting from 1 to 10 repetitively, while they took a deep breath during DB. Physiological indices were simultaneously recorded with a biofeedback system.

Results: Respiration rate, thoracic amplitude, and mean heart rate decreased in RB compared with UB, but there was no change in HRV. Respiration rate in $\mathrm{BCM}$ and $\mathrm{DB}$ was lower than that in $\mathrm{UB}$ or RB, and the amplitude of thorax or abdomen, and HRV all increased $(\mathrm{p}<0.05)$. However, mean heart rate and skin conductance decreased in $\mathrm{BCM}$ compared with UB $(\mathrm{p}<0.05)$, whereas those were no different between DB and UB.

Conclusion: BCM, just concentrating mentally on breathing with counting each breath, can increase HRV with less sympathetic activation, while DB, actively moving thorax and abdomen for achieving the deepest respiration rate, can greatly raise HRV with the maintenance of mean vagal or sympathetic tone.
\end{abstract}

Key Words : Usual breathing, Relaxing breathing, Breath-counting meditation, Deep breathing, Heart rate variability, Biofeedback

\section{Introduction}

Respiration is naturally controlled by a pacemaker in the brain stem that receives signals from the autonomic nervous system, chemoreflexes, and baroreflexes generated by exercise, stress, and temperature changes. However, it can also be controlled consciously; individuals can control respiration rate, volume of each breath, ratio of inspiration and expiration, etc. [1]. Consciously controlled breathing affects mind and body, and acts as an important component of meditations such as breathing awareness meditation [2], yoga [3], Dantian breathing [4], and mindfulness meditation [5].

Some previous studies used the direction of listening [6] or sight [7] for controlling participants' respiration rate. This method has an advantage in

\footnotetext{
- Received : 12 May 2016 - Revised : 16 June $2016 \quad$ Accepted : 16 June 2016

- Correspondence to: Seong-Sik Park

Dept. of Sasang Constitutional Medicine, Dongguk university Bundang hospital of Korean Medicine 268, Buljeong-ro, Bundang-gu, Seongnam-si, Gyeonggi-do, Rep. of Korea

Tel : +82-10-3359-8421, E-mail : parkss@dongguk.ac.kr
} 
that the respiration rates of participants can be matched as fixed pace. However, paced deep breathing caused stress in $60 \%$ of study participants [8], and autonomic nervous input heightened by this stress could lower heart rate variability (HRV) [9]. The occurrence of physical problems such as functional digestive disorders [10], inflammation [11], and hypertension [12] may correspond with a lower HRV. It is worthy to find how HRV can be increased effectively by breathing technique.

Therefore, we chose breath-counting meditation (BCM) and deep breathing (DB) among non-paced and self-controlled breathing techniques. BCM is a type of Zen meditation called Su-soku; it is performed by concentrating mentally on breathing while counting each breath [13]. On the other hand, in $\mathrm{DB}$, participants concentrate physically on breathing while participants consciously maximize inspiration and expiration [14]. In order to observe the effect of these on HRV, we evaluated various physiological indices including respiration rate, the amplitude of thorax and abdomen, mean heart rate, skin conductance (SC) and body temperature with HRV while participants performed BCM and DB. We also compared usual breathing (UB) and relaxing breathing (RB) with those in order to reveal the characteristics of $\mathrm{BCM}$ and $\mathrm{DB}$.

\section{Materials and Methods}

\section{Participants}

83 young men and women attending Dongguk University were enrolled in this study (45 males, 38 females, average age 26.07 \pm 4.06 ). All participants were given a full explanation of the study and completed an informed consent form confirming participation of their own free will. Participants responded to questions regarding their health status, past disease history, and medication use. Participants had no previous experience with yoga or meditation, and did not have any respiratory, cardiovascular or autonomic diseases. Participants were allowed to eat breakfast 2 hours before the beginning of the study. However, all substances that may cause physiological changes, including coffee, were prohibited 12 hours prior to the study. One woman did not complete measurements of HRV, and dropped out of the study. Therefore, a total of 82 participants completed the study (Figure 1).

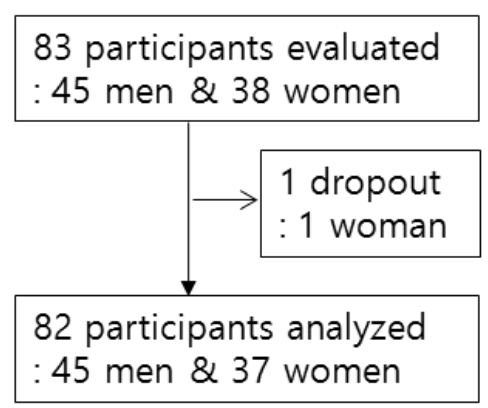

Fig. 1. Participants' flow

Forty five men and 38 women were recruited. One woman did not complete measurements, and dropped out of the study. Therefore, total 82 participants ( 45 men and 37 women) were statistically analyzed.

\section{Outcome Measures}

All measurements were digitized and recorded with the ProComp biofeedback system (Korea medical technology, http://www.kmtec.com, Republic of Korea). Respiration rate, the amplitude of thorax and abdomen were measured using respiratory inductive plethysmography(RIP) belts strapped to the thorax and abdomen. Mean heart rate, standard deviation of heart rate, standard deviation of normal intervals (SDNN), low frequency (LF; 0.04 0.15Hz), and high frequency (HF; $0.15 \sim 0.4 \mathrm{~Hz}$ ) were measured using an infrared photo plethysmography machine attached to the left middle finger. SC and body temperature were measured with sensors on the left index and ring finger. 


\section{Procedures}

Testing was performed in a quiet room between 9 a.m. and 11 a.m. Before the study, the participants were educated on the characteristics of each breathing method and practiced the methods with an investigator trained in advance. Afterwards, when the participants were resting while sitting in chairs, the investigator attached the measuring tools to participants' bodies. The participants then performed $\mathrm{UB}, \mathrm{RB}, \mathrm{BCM}$, and $\mathrm{DB}$ for 5 minutes each at the direction of the investigator. 1 minute of relaxation was permitted between each method. For UB, the participant was told to surf the internet using a mouse with right hand while sitting in front of a computer monitor. For RB, the participant with eyes closed breathed naturally while trying not to think of anything in particular. For BCM, the participant with eyes closed counted from 1 to 10 repetitively during expiration. For DB, the participant took a deep breath and concentrate just on physical act consciously for controlling respiration. All procedures were performed under the approval of the Institutional Review Board (IRB) of Dongguk University.

\section{Statistical Analyses}

Data was analyzed with SPSS (IBM SPSS Inc. version 20). The results of LF and HF were skewed; therefore, they were analyzed after natural log-transformation ( $\operatorname{lnLF}$ and $\operatorname{lnHF}$, respectively). Repeated measures- analysis of variance (RM-ANOVA) was performed in order to compare breathing methods. When the sphericity assumption was not satisfied, significance was tested after correcting for the number of degrees of freedom using Greenhouse-Geisser'se-corrected degrees of freedom. Post-hoc analysis was performed using Fisher's Least Significant Difference (LSD) method. Results were judged to be statistically significant if the a value was less than $0.05(\mathrm{p}<0.05)$, and are shown as mean \pm S.D.

\section{Results}

We performed RM-ANOVA for the measured physiological indices. Post-hoc analyses of the statistically significant indices are presented in this section and summarized in Table 1.

Respiration rate significantly decreased in the following order: $\mathrm{UB}, \mathrm{RB}, \mathrm{BCM}$, and $\mathrm{DB}(\mathrm{p}<0.05)$. Respiration rate was lowest in DB (Figure 1). Thoracic amplitude was significantly lower during RB compared with UB and BCM $(\mathrm{p}<0.05)$, and was the highest during $\mathrm{DB}(\mathrm{p}<0.05)$. However, there was no statistically significant difference between UB and BCM. Abdominal amplitude was significantly greater in $\mathrm{BCM}$ compared with $\mathrm{RB}(\mathrm{p}<0.05)$, and was the highest in DB $(\mathrm{p}<0.05)$. However, abdominal amplitude was not significantly different between UB and either RB or BCM. Mean heart rate significantly decreased in the following order: $\mathrm{UB}, \mathrm{RB}$, and $\mathrm{BCM}$ $(p<0.05)$. The mean heart rate in $D B$ was higher than that of $\mathrm{RB}$ or $\mathrm{BCM}(\mathrm{p}<0.05)$, and showed no difference compared with UB (Figure 2). The standard deviation of heart rate was significantly higher for DB compared with all other conditions $(p<0.05)$. SDNN, $\operatorname{lnLF}$, and $\operatorname{lnHF}$ were all significantly increased in $\mathrm{BCM}$ and $\mathrm{DB}$ compared with UB or $\mathrm{RB} \quad(\mathrm{p}<0.05)$. Those in $\mathrm{DB}$ was especially increased compared with $\mathrm{BCM}(\mathrm{p}<0.05)$. However, there was no statistically significant difference between UB and RB (Figure 3). SC was higher in $\mathrm{UB}$ and $\mathrm{DB}$ compared with $\mathrm{RB}$ or $\mathrm{BCM}$ $(p<0.05)$. However there was no significant difference in $\mathrm{SC}$ between $\mathrm{UB}$ and $\mathrm{DB}$, or between $\mathrm{RB}$ and $\mathrm{BCM}$ (Figure 4). Body temperature significantly increased in the following order: UB, $\mathrm{RB}$, and $\mathrm{BCM}(\mathrm{p}<0.05)$. However, there was no difference between DB and UB.

\section{Discussion}

The purpose of this study was to evaluate the 
Table 1. Physiological Indices Obtained from the Results of Four Breathing States

\begin{tabular}{|c|c|c|c|c|c|c|}
\hline $\begin{array}{c}\text { Measure } \\
\text { (Mean } \pm \text { S.D.) }\end{array}$ & $\begin{array}{l}\text { Usual breath } \\
\text { (UB) }\end{array}$ & $\begin{array}{l}\text { Relaxing } \\
\text { Breath } \\
\text { (RB) }\end{array}$ & $\begin{array}{l}\text { Breath-counting } \\
\text { meditation } \\
(\mathrm{BCM})\end{array}$ & $\begin{array}{l}\text { Deep } \\
\text { breathing } \\
\text { (DB) }\end{array}$ & RM-ANOVA & $\begin{array}{l}\text { Post hoc } \\
(p<0.05)\end{array}$ \\
\hline $\begin{array}{l}\text { Respiration Rate } \\
\text { (breaths } / \mathrm{min} \text { ) }\end{array}$ & $\begin{array}{c}15.72 \\
\pm 1.59^{\mathrm{d}}\end{array}$ & $\begin{array}{l}14.34 \\
\pm 2.47^{\mathrm{c}}\end{array}$ & $\begin{array}{c}13.53 \\
\pm 3.00^{\mathrm{b}}\end{array}$ & $\begin{array}{c}8.51 \\
\pm 2.61^{\mathrm{a}}\end{array}$ & $\begin{array}{c}\mathrm{F}(3,808.98)=166.95 \\
\mathrm{p}=0.000\end{array}$ & $\begin{array}{c}\text { UB-RB } \\
\text { UB-BCM } \\
\text { UB-DB } \\
\text { RB-BCM } \\
\text { RB-DB } \\
\text { BCM-DB }\end{array}$ \\
\hline $\begin{array}{l}\text { Thoracic amplitude } \\
\qquad(\mathrm{cm})\end{array}$ & $\begin{array}{c}1.81 \\
\pm 0.79^{\mathrm{b}}\end{array}$ & $\begin{array}{c}1.56 \\
\pm 0.79^{\mathrm{a}}\end{array}$ & $\begin{array}{c}1.86 \\
\pm 1.27^{\mathrm{b}}\end{array}$ & $\begin{array}{c}7.07 \\
\pm 3.78^{\mathrm{c}}\end{array}$ & $\begin{array}{c}\mathrm{F}(1.20,1454.51)=171.30 \\
\mathrm{p}=0.000 \\
\varepsilon=0.400\end{array}$ & $\begin{array}{c}\text { UB-RB } \\
\text { UB-DB } \\
\text { RB-BCM } \\
\text { RB-DB } \\
\text { BCM-DB }\end{array}$ \\
\hline $\begin{array}{l}\text { Abdominal amplitude } \\
\text { (cm) }\end{array}$ & $\begin{array}{c}2.88 \\
\pm 1.27^{\mathrm{ab}}\end{array}$ & $\begin{array}{c}2.68 \\
\pm 1.23^{\mathrm{a}}\end{array}$ & $\begin{array}{c}3.23 \\
\pm 2.06^{\mathrm{b}}\end{array}$ & $\begin{array}{c}10.18 \\
\pm 5.41^{\mathrm{c}}\end{array}$ & $\begin{array}{c}\mathrm{F}(1.27,2557.11)=159.04 \\
\mathrm{p}=0.000 \\
\varepsilon=0.423\end{array}$ & $\begin{array}{l}\text { UB-DB } \\
\text { RB-BCM } \\
\text { RB-DB } \\
\text { BCM-DB }\end{array}$ \\
\hline $\begin{array}{l}\text { Mean Heart rate } \\
\text { (beats/min) }\end{array}$ & $\begin{array}{l}75.06 \\
\pm 9.64^{\mathrm{c}}\end{array}$ & $\begin{array}{l}73.31 \\
\pm 9.62^{\mathrm{b}}\end{array}$ & $\begin{array}{l}71.98 \\
\pm 9.39^{\mathrm{a}}\end{array}$ & $\begin{array}{r}75.41 \\
\pm 8.58^{\mathrm{c}}\end{array}$ & $\begin{array}{c}\mathrm{F}(1.89,332.41)=18.49 \\
\mathrm{p}=0.000 \\
\varepsilon=0.628\end{array}$ & $\begin{array}{c}\text { UB-RB } \\
\text { UB-BCM } \\
\text { RB-BCM } \\
\text { RB-DB } \\
\text { BCM-DB }\end{array}$ \\
\hline $\begin{array}{l}\text { Standard deviation } \\
\text { of heart rate } \\
\text { (beats/min) }\end{array}$ & $\begin{array}{c}5.54 \\
\pm 3.45^{\mathrm{a}}\end{array}$ & $\begin{array}{c}5.04 \\
\pm 1.84^{\mathrm{a}}\end{array}$ & $\begin{array}{c}5.24 \\
\pm 2.38^{\mathrm{a}}\end{array}$ & $\begin{array}{c}9.10 \\
\pm 4.86^{\mathrm{b}}\end{array}$ & $\begin{array}{c}\mathrm{F}(2.11,432.49)=44.60 \\
\mathrm{p}=0.000 \\
\varepsilon=0.702\end{array}$ & $\begin{array}{c}\text { UB-DB } \\
\text { RB-DB } \\
\text { BCM-DB }\end{array}$ \\
\hline $\begin{array}{l}\text { Standard Deviation of } \\
\text { N-N Interval }(\mathrm{ms})\end{array}$ & $\begin{array}{c}55.07 \\
\pm 26.53^{\mathrm{a}}\end{array}$ & $\begin{array}{c}56.15 \\
\pm 23.16^{\mathrm{a}}\end{array}$ & $\begin{array}{c}60.13 \\
\pm 27.97^{\mathrm{b}}\end{array}$ & $\begin{array}{c}96.44 \\
\pm 50.60^{\mathrm{c}}\end{array}$ & $\begin{array}{c}\mathrm{F}(1.52,63342.53)=56.22 \\
\mathrm{p}=0.000 \\
\varepsilon=0.507\end{array}$ & \multirow{3}{*}{$\begin{array}{c}\text { UB-BCM } \\
\text { UB-DB } \\
\text { RB-BCM } \\
\text { RB-DB } \\
\text { BCM-DB }\end{array}$} \\
\hline $\ln \mathrm{LF}\left(\mathrm{ms}^{2}\right)$ & $\begin{array}{c}5.03 \\
\pm 0.84^{\mathrm{a}}\end{array}$ & $\begin{array}{c}4.92 \\
\pm 0.89^{\mathrm{a}}\end{array}$ & $\begin{array}{c}5.20 \\
\pm 0.97^{\mathrm{b}}\end{array}$ & $\begin{array}{c}6.34 \\
\pm 1.20^{\mathrm{c}}\end{array}$ & $\begin{array}{c}\mathrm{F}(2.21,47.66)=75.71 \\
\mathrm{p}=0.000 \\
\varepsilon=0.736\end{array}$ & \\
\hline $\ln \mathrm{HF}\left(\mathrm{ms}^{2}\right)$ & $\begin{array}{c}4.74 \\
\pm 1.06^{\mathrm{a}}\end{array}$ & $\begin{array}{c}4.76 \\
\pm 0.94^{\mathrm{a}}\end{array}$ & $\begin{array}{c}4.98 \\
\pm 1.02^{\mathrm{b}}\end{array}$ & $\begin{array}{c}5.58 \\
\pm 1.29^{\mathrm{c}}\end{array}$ & $\begin{array}{c}\mathrm{F}(2.37,15.79)=22.78 \\
\mathrm{p}=0.000 \\
\varepsilon=0.789\end{array}$ & \\
\hline $\begin{array}{l}\text { Skin conductance } \\
(\mu \mathrm{V})\end{array}$ & $\begin{array}{c}0.95 \\
\pm 1.06^{\mathrm{b}}\end{array}$ & $\begin{array}{c}0.76 \\
\pm 0.80^{\mathrm{a}}\end{array}$ & $\begin{array}{c}0.73 \\
\pm 0.95^{\mathrm{a}}\end{array}$ & $\begin{array}{c}1.09 \\
\pm 1.54^{\mathrm{b}}\end{array}$ & $\begin{array}{c}\mathrm{F}(1.65,4.22)=6.61 \\
\mathrm{p}=0.003 \\
\varepsilon=0.548\end{array}$ & $\begin{array}{l}\text { UB-RB } \\
\text { UB-BCM } \\
\text { RB-DB } \\
\text { BCM-DB }\end{array}$ \\
\hline $\begin{array}{l}\text { Body temperature } \\
\left({ }^{\circ} \mathrm{C}\right)\end{array}$ & $\begin{array}{l}32.96 \\
\pm 1.89^{\mathrm{a}}\end{array}$ & $\begin{array}{c}33.34 \\
\pm 1.39^{\mathrm{b}}\end{array}$ & $\begin{array}{c}33.50 \\
\pm 1.16^{\mathrm{c}}\end{array}$ & $\begin{array}{c}33.03 \\
\pm 1.31^{\mathrm{a}}\end{array}$ & $\begin{array}{c}\mathrm{F}(1.46,10.77)=8.56 \\
\mathrm{p}=0.001 \\
\varepsilon=0.487\end{array}$ & $\begin{array}{c}\text { UB-RB } \\
\text { UB-BCM } \\
\text { RB-BCM } \\
\text { RB-DB } \\
\text { BCM-DB }\end{array}$ \\
\hline
\end{tabular}

effect of BCM and DB on HRV using a non-paced and self-controlled breathing method. UB and RB could reveal the characteristics of those by comparison.

In our study, in RB compared with UB, mean 
(208) Journal of Korean Medicine 2016;37(2)

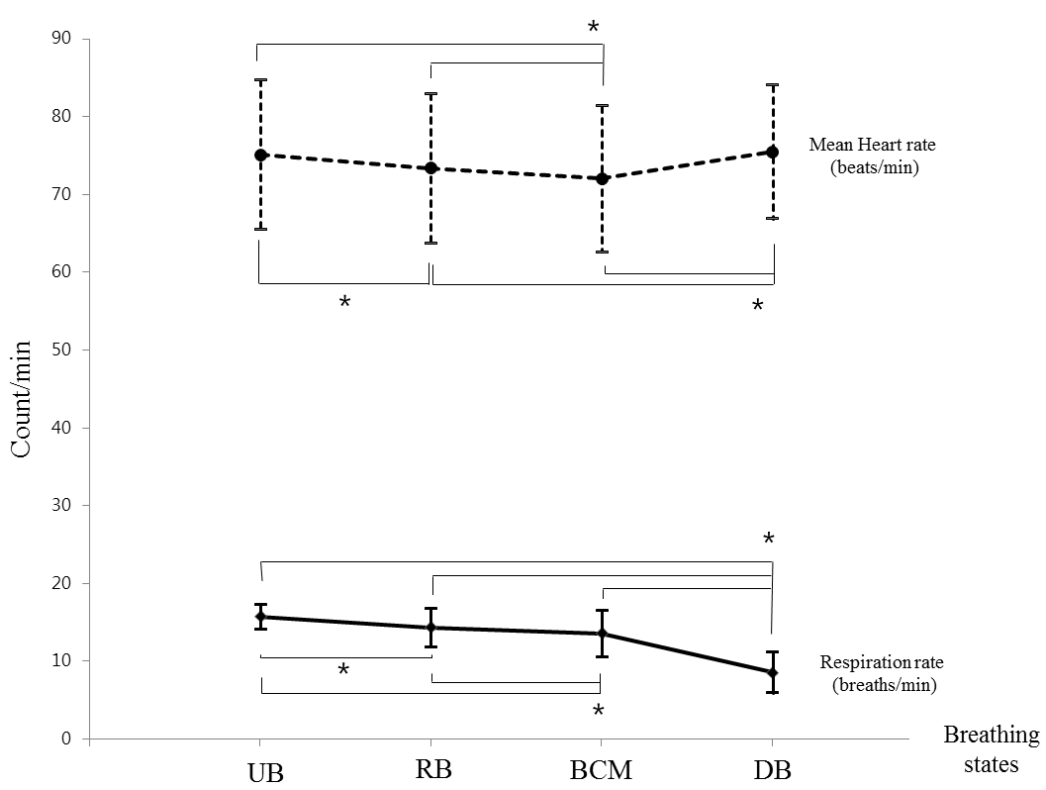

Fig. 2. Changes of mean heart rate and respiration rate according to four breathing states

The mean heart rate became statistically and significantly lower as UB progressed toward RB and BCM ( $p<0.05)$. It was statistically and significantly higher for DB compared with RB and BCM $(p<0.05)$, but was not significantly different regarding UB. Contrarily, the respiration rate became statistically, significantly, and gradually lower as UB progressed toward RB, BCM, and DB $(p<0.05)$.

UB: Usual breathing; RB: Relaxing breathing; BCM: Breath-counting meditation; DB: Deep breathing $\star p<0.05$

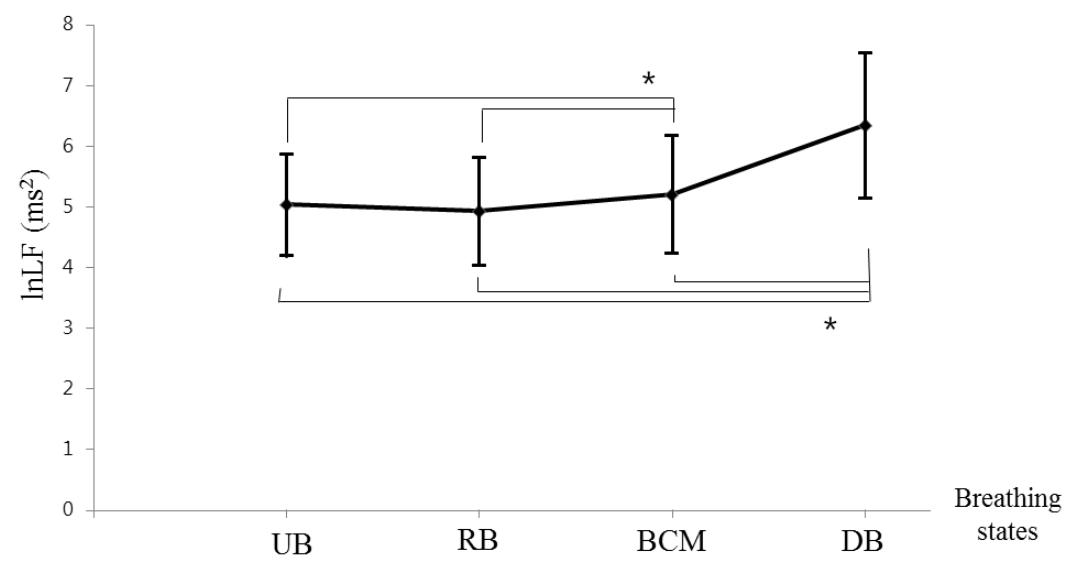

Fig. 3. Changes of standard deviation of $\mathrm{N}-\mathrm{N}$ interval (SDNN) and low frequency (LF) component of Heart rate variability (HRV) according to four breathing states

a) In the SDNN, there was no statistically significant difference for both UB and RB, but it showed a statistically significant increase pattern for BCM $(p<0.05)$, and these indices tended to increase more for DB compared with BCM $(p<0.05)$.

b) The changes of InLFalsoshowed the same tendency as SDNN. This tendency was the same for InHF(Figure not shown)

SDNN: Standard deviation of $\mathrm{N}-\mathrm{N}$ interval

In: Natural logarithm

LF: Low frequency $(0.04 \sim 0.15 \mathrm{~Hz})$ component of Heart rate variability (HRV)

$\mathrm{HF}$ : High frequency $(0.15 \sim 0.4 \mathrm{~Hz})$ component of Heart rate variability (HRV)

UB: Usual breathing; RB: Relaxing breathing; BCM: Breath-counting meditation; DB: Deep breathing $\star p<0.05$ 


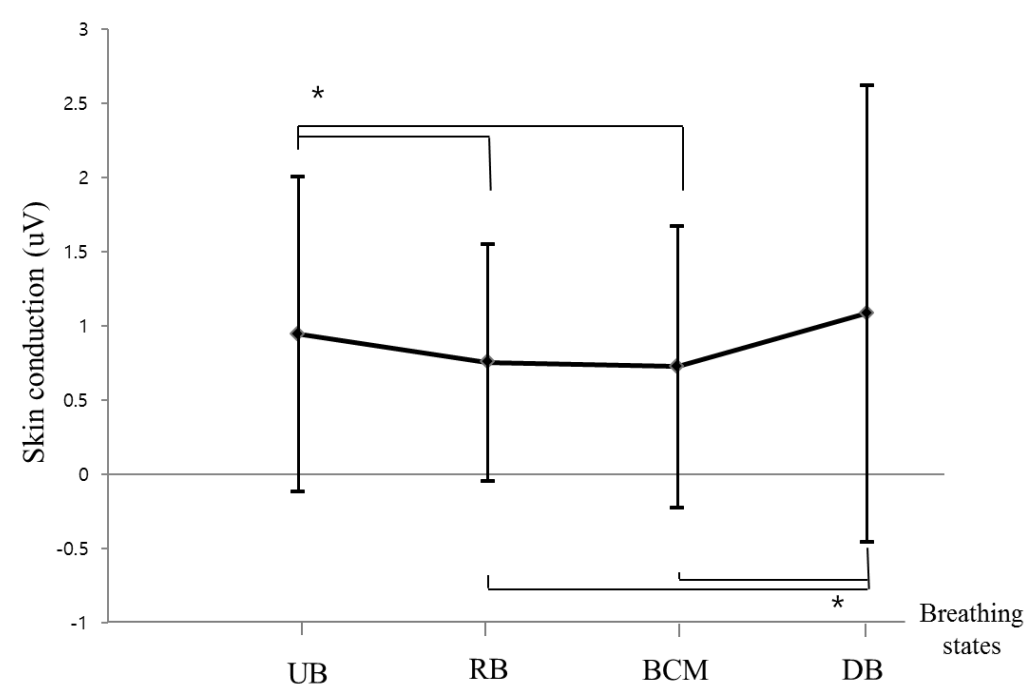

Fig. 4. Changes of skin conductance according to four breathing states

In skin conductance, UB was statistically significant compared with RB and BCM ( $p<0.05)$. DB was also statistically significant compared with $\mathrm{RB}$ and $\mathrm{BCM}(p<0.05)$. However, there was no statistically significant difference between UB and DB and between RB and BCM.

UB: Usual breathing; RB: Relaxing breathing; BCM: Breath-counting meditation; DB: Deep breathing $* p<0.05$

heart rate, and SC decreased, and body temperature increased according to the decrease of respiration rate and thoracic amplitude. Sympathetic activity in body can be indirectly observed via SC. In a relaxed, stress-free state, sympathetic activity is reduced, which reduces perspiration [15]. The decrease of SC reflects that participants were less sympathetically activated when performing $\mathrm{RB}$ than UB. In conclusion, mean heart rate decreased, and body temperature increased with less sympathetic activity. However, SDNN, LF, and HF were similar in $\mathrm{RB}$ and $\mathrm{UB}$, so this change seems to be insufficient to change HRV.

In BCM compared with RB, SDNN, LF, and HF all increased with both the decrease of respiration rate and the increase of thoracic and abdominal amplitude. SC was not statistically different between $\mathrm{RB}$ and $\mathrm{BCM}$. It looked like participants similarly relaxed in both $B C M$ and $R B$, but unlike $R B, B C M$ could increase HRV although participants just concentrated mentally on breathing with counting each breath. The amplitude of RSA is inversely proportional to respiration rate and is tidal volume dependent under certain conditions [16]. Respiration rate was slower during $\mathrm{BCM}$ than during $\mathrm{RB}$. The enough higher thoracic and abdominal amplitude in $\mathrm{BCM}$ than $\mathrm{RB}$ could result in the increase of tidal volume. LF is primarily under vagal control, although some research suggests a component of sympathetic mediation [17]. LF also is influenced by the baroreflex, by which heart rate is affected by changes in arterial blood pressure [18]. HF reflects respiratory sinus arrhythmia (RSA) by parasympathetic nervous reaction to changes in respiration [19]. SDNN is related to the R-R interval [20]. SDNN and total power are measures of overall change in HRV [21]. Therefore, active changes of thorax and abdomen may influence baroreflex, resulting in the increase of LF, HF, and SDNN. BCM and RB are active relaxation procedures that might decrease sympathetic arousal, while only BCM may increase HRV. 
In DB, standard deviation of the heart rate, LF, $\mathrm{HF}$, and SDNN all were greatly increased. Participants took in the fewest breaths during DB. If the respiration rate decreases and approaches the LF range, RSA due to respiration and LF related to the baroreflex can overlap, causing great variability in heart rate [22]. In states of slow respiration rate such as DB ( $8.51 \pm 2.61$ breaths $/ \mathrm{min})$, the increased RSA can also influence LF [23]. The respiration rate of DB among the tested breathing states was closest to $0.1 \mathrm{~Hz}$ (6 breaths $/ \mathrm{min}$ ), 'the resonance frequency of the cardiovascular system', at which the maximal oscillation of heart rate can be produced by paced breathing [24]. Therefore, HRV significantly increased in DB actively changing the amplitude of thorax and abdomen with the slowest respiration rate. However, In $\mathrm{DB}, \mathrm{SC}$ and body temperature were maintained at levels seen in $\mathrm{UB}$, and the mean heart rate in $\mathrm{DB}$ was not statistically different from that in UB. This means that the degree of sympathetic activation in DB is similar to UB. It is not necessarily changed in autonomic nerves' traffic in order to increase the amplitude of RSA because the slower respiration rates help acetylcholine from vagal nerve ending more fully hydrolyzed [25] or because vagal efferent traffic can be affected on heart with the phasic pattern due to the longer expiration period [26]. Therefore, HRV can increase without the change of 'mean' autonomic pattern and 'mean' heart rate.

Our study has some limitations. First, the breathing methods were not performed in a random order. Instead, they were performed in the order of increasing intervention such as BCM followed by DB. One-minute resting time between each method may also reduce influences by the preceding breathing. Second, we had no choice but to rely entirely on the participants' compliance with the investigators' instructions because our study incorporated non-paced breathing in order to rule out the possibility of stress induced by paced breathing methods. Well-designed, additional studies are needed in the future.

\section{Conclusion}

Compared with UB in the daily living condition, both $\mathrm{BCM}$ and $\mathrm{DB}$ could make the decrease in respiration rate. Mean heart rate and $\mathrm{SC}$ decreased in BCM compared with $\mathrm{UB}$, while in $\mathrm{DB}$, those were not statistically different from UB. SDNN, LF, and $\mathrm{HF}$ more increased in both $\mathrm{BCM}$ and $\mathrm{DB}$ than UB. BCM could increase HRV unlike RB, although those were both active relaxation procedures. Therefore, our study showed that BCM, just concentrating mentally on breathing with counting each breath, can increase HRV with less sympathetic activation than $\mathrm{UB}$, while DB, actively moving thorax and abdomen for achieving the deepest respiration rate, can greatly raise $\mathrm{HRV}$ with the maintenance of mean vagal or sympathetic tone at the level of UB.

\section{Conflicts of interest}

The authors declare no conflicts of interest.

\section{Acknowledgement}

This work was supported by a National Research Foundation of Korea Grant funded by the Korean Government (NRF-2014S1A5B6A02049047).

\section{References}

1. Benchetrit G. Breathing pattern in humans: diversity and individuality. Respir Physiology. 2000;122(2-3):123-9.

2. Barnes VA, Pendergrast RA, Harshfield GA, Treiber FA. Impact of breathing awareness meditation on ambulatory blood pressure and sodium handling in prehypertensive African American adolescents.Ethnicity \& Disease. 2008; 18(1):1-5. 
3. Brown RP, Gerbarg PL. Yoga breathing, meditation, and longevity. Annals of the New York Academy of science. 2009;1172:54-62.

4. Chan AS, Cheung M-C, Sze SL, Leung WW-M, Shi D. Shaolin dantian breathing fosters relaxed and attentive mind: a randomized controlled neuro-electrophysiological study. Evid Based Complement Alternat Med. 2001;180704.

5. Ando M, Morita T, Akechi T, Ifuku Y. A qualitative study of mindfulness-based meditation therapy in Japanese cancer patients. Support Care Cancer. 2011;19(7):929-33.

6. Driscoll D, Dicicco G. The effects of metronome breathing on the variability of autonomic activity measurements. J Manipulative Physiol Ther. 2000;23(9):610-4.

7. Cooke WH, Cox JF, Diedrich AM, Taylor JA, Beightol LA, Ames JE, et al. Controlled breathing protocols probe human autonomic cardiovascular rhythms. Am J Physiol. 1998;274(2):H709-18.

8. Khan HM, Ahmed B, Choi J, Gutierrez-Osuna R. Using an ambulatory stress monitoring device to identify relaxation due to untrained deep breathing. Conf Proc Annu Int Conf IEEE Eng Med Biol Soc. IEEE Eng Med Biol Soc Annu Conf. 2013;1744-7.

9. Taylor JA, Myers CW, Halliwill JR, Seidel H, Eckberg DL. Sympathetic restraint of respiratory sinus arrhythmia: implications for vagal-cardiac tone assessment in humans. Am J Physiol Heart Circ Physiol. 2001;280:H2804-14.

10. Gevirtz R. The Promise of Heart Rate Variability Biofeedback: Evidence-Based Applications. Biofeedback. 2013;41(3):110-20.

11. Jan BU, Coyle SM, Oikawa LO, Lu S-E, Calvano SE, Lehrer PM, et al. Influence of acute epinephrine infusion on endotoxin-induced parameters of heart rate variability: a randomized controlled trial. Ann Surg. 2009;249(5):750-760.

12. Schroeder EB, Liao D, Chambless LE, Prineas RJ, Evans GW, Heiss G. Hypertension, Blood
Pressure, and Heart Rate Variability The Atherosclerosis Risk in Communities (ARIC) Study. Hypertension. 2003;42(6):1106-11.

13. Chiesa A. Zen meditation: an integration of current evidence. J Altern Complement Med. 2009;15(5):585-92.

14. Busch V, Magerl W, Kern U, Haas J, Hajak G, Eichhammer P. The effect of deep and slow breathing on pain perception, autonomic activity, and mood processing-an experimental study. Pain Med Malden Mass. 2012;13(2):215-28.

15. Turankar AV, Jain S, Patel SB, Sinha SR, Joshi $\mathrm{AD}$, Vallish $\mathrm{BN}$, et al. Effects of slow breathing exercise on cardiovascular functions, pulmonary functions \& galvanic skin resistance in healthy human volunteers - a pilot study. Indian J Med Res. 2013;137(5):916-21.

16. Hirsch JA, Bishop B. Respiratory sinus arrhythmia in humans: how breathing pattern modulates heart rate. Am J Physiol. 1981;241(4):.H620-9.

17. Rahman F, Pechnik S, Gross D, Sewell L, Goldstein DS. Low frequency power of heart rate variability reflects baroreflex function, not cardiac sympathetic innervation. ClinAuton Res. 2011;21(3):133-41.

18. Perini R, Veicsteinas A. Heart rate variability and autonomic activity at rest and during exercise in various physiological conditions. Eur J Appl Physiol. 2003;90(3-4):317-25.

19. Task Force of the European Society of Cardiology and the North American Society of Pacing and Electrophysiology. Heart rate variability, Standards of measurement, physiological interpretation, and clinical use.Eur Heart J. 1996;17(3):354-81.

20. Coumel P, Maison-Blanche P, Catuli D. Heart rate and heart rate variability in normal young adults. J Cardiovasc Electrophysiol. 1994;5(11): 899-911.

21. Sztajzel J. Heart rate variability: a noninvasive electrocardiographic method to measure the 
autonomic nervous system. Swiss Med Wkly. 2004;134(35-36):514-22.

22. Malliani A. Heart rate variability: from bench to bedside. Eur J Intern Med. 2005;16(1):12-20.

23. Prinsloo GE, Derman WE, Lambert MI, Laurie Rauch HG. The effect of a single session of short duration biofeedback-induced deep breathing on measures of heart rate variability during laboratory -induced cognitive stress: a pilot study. Appl Psychophysiol Biofeedback. 2013; 38:81-90.
24. Vaschillo EG, Vaschillo B, Lehrer PM. Characteristics of resonance in heart rate variability stimulated by biofeedback. Appl Psychophysiol Biofeedback, 2006;31(2):129-42.

25. Eckberg DL, Eckberg MJ. Human sinus node responses to repetitive, ramped carotid baroreceptor stimuli. Am J Physiol. 1982;242(4):H638-44.

26. Grossman P, Taylor EW. Toward understanding respiratory sinus arrhythmia: relations to cardiac vagal tone, evolution and biobehavioral functions. Biol Psychol. 2007;74(2):263-85. 